MATEC Web of Conferences 25, 04003 (2015)

DOI: $10.1051 /$ matecconf/ 20152504003

(c) Owned by the authors, published by EDP Sciences, 2015

\title{
Control of City Shallow Buried Tunnel Blasting Hazard to Surface Buildings
}

\author{
Deqiang Yang \\ School of Civil and Environmental Engineering, University of Science and Technology Beijing, Beijing, China; \\ Guizhou Xinlian Blasting Engineering Group Co Ltd, Guizhou, Guiyang, China; \\ Beijing General Research Institute of Ming \& Metallurgy, Beijing, China \\ Enan Chi \\ Guizhou Xinlian Blasting Engineering Group Co Ltd, Guizhou, Guiyang, China \\ Yucheng Ji \& Jia Liu \\ School of Civil and Environmental Engineering, University of Science and Technology Beijing, Beijing, China \\ Xuguang Wang \\ Beijing General Research Institute of Ming \& Metallurgy, Beijing, China \\ Mingsheng Zhao \& Tiejun Tao \\ Guizhou Xinlian Blasting Engineering Group Co Ltd, Guizhou, Guiyang, China \\ Yang Wang \\ School of Civil and Environmental Engineering, University of Science and Technology Beijing, Beijing, China
}

\begin{abstract}
Combining with the blasting test of an under-construction tunnel, this paper optimizes the overall blasting construction scheme. The optimized blasting scheme is used in the site construction test and the peak particle vibration velocity is strictly controlled under working conditions through blasting vibration monitoring to ensure the safety of surrounding buildings and structures in the construction process. The corresponding control measures are proposed to reduce the blasting vibration which brings certain guiding significance to the following construction project.
\end{abstract}

Keywords: tunnel blasting; blasting optimization; vibration monitoring; control measures

\section{INTRODUCTION}

With the development of transportation industry in our country, there will be shallower and shallower tunnel projects going through downtown area, under the restriction of engineering and geological conditions, the tunnel blasting method is adopted in most of the construction. Compared with other blasting project, the tunnel blasting construction carried out in shallow buried depth always has closer distance from the explosion source to ground building (structure), which made the blasting vibration problem become more prominent and increase the difficulty and risks of construction blasting. With slight mistakes of construction measures, the blasting vibration may cause walls and concrete to be cracked and cause paint loss, glass doors and windows to be broken, which seriously endangered the safety of building. The excessive blasting vibration may also cause buildings to be collapsed, bringing catastrophic consequences. During the excavation of shallow buried tunnel, the excessively conservative blasting vibration control measures will undoubtedly meet the requirements of safety production. However, this is bound to cause large increase in construction costs and dramatically reduce the efficiency of construction, and from the economic point of view, it is extremely unreasonable. Based on the above factors, this paper optimizes the blasting construction scheme combined with the shallow buried tunnel blasting test in a certain city and then controls the harm of blasting vibration on the surface buildings.

\section{EFFECTS OF BLASTING DAMAGE}

A large number of engineering practice and studies have shown that the blasting damage or injury of buildings (structures) is a comprehensive reflection of their own characteristics, site conditions and structural characteristics of the blasting projects, not only related with the blasting intensity, frequency and duration, but also with transmission medium, site characterization, dynamic response characteristics of construction (structure) and cumulative effects of blasting. Therefore, using a single vibration intensity 


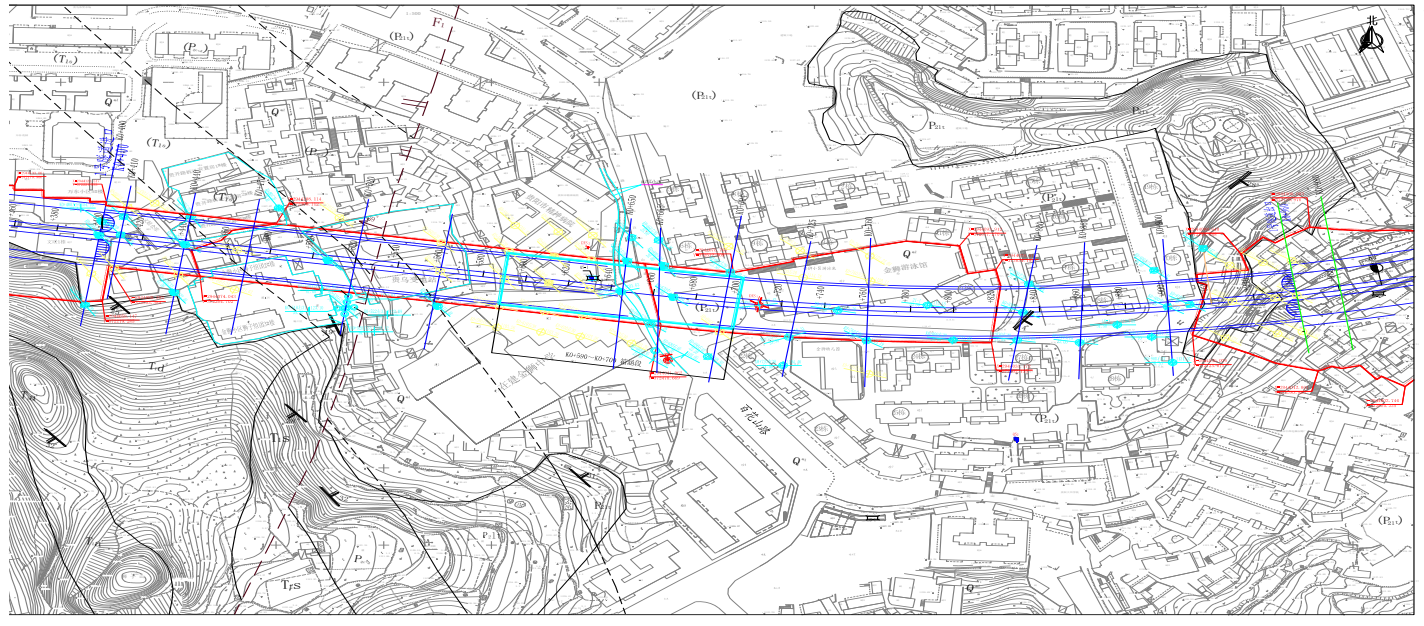

Figure 1. Construction plan

factor (vibration displacement, velocity, acceleration) as safety criterion cannot meet the actual project needs, and it is being questioned by many researchers. The describing parameters of ground motion intensity and damage potential should be able to reflect the characteristics of ground motion, and the peak acceleration, effective duration and characteristic period can also reflect ground motion characteristics ${ }^{[6,7]}$. Studies show that the seismic total input energy is closely related to these parameters ${ }^{[8,9]}$, which is an important indicator reflecting the ground motion damage potential, not only related with the characteristics of the ground motion itself, but also with its own structure characteristics. The parameter of the ground motion input energy is relatively stable, and the structural features in addition to the natural vibration period and the influence of other factors such as damping and ductility is small ${ }^{[10-12]}$. This paper is still using the peak particle vibration as the safety criterion of blasting vibration research.

\section{ENGINEERING SITUATION}

The Beijing East Road Project is located in the east of Guiyang City. According to Guizhou Daily, the starting point which is located at the intersection of Beijing Road and Baoshan Road is across the Lion Mountain, Baihua Mountain, Wufeng Mountain and Zhoujia Mountain. Then it is down-traversing the Baihuashan Road and across the proposed east second ring road, Shidong Road and Nanming River, down-traversing the ring expressway. It is extended from east to west and finally ended at Ali village turn. The total length of the road is $7384.61 \mathrm{~m}$ and the width is $40 \mathrm{~m}$. The road is designed with two-way six-lane. The whole line sets two short chains. The left pile of ZK2 + $023.846=$ ZK2 +040 (short-chain: $16.155 \mathrm{~m}$ ) and the right pile of $\mathrm{K} 1+982.606=\mathrm{K} 2+000$ (short-chain: $17.394 \mathrm{~m}$ ). The road is three-layer structure of asphalt concrete pavement. The vehicle load is designed as "city A-class." The road is a three-layer structure of asphalt concrete pavement. The whole line has three bridges and three tunnels. The construction plan is shown in Figure 1.

This paper only carried out research on controlling the damage and effect of blasting vibration on surface buildings in Beijing East Road No.1 tunnel of Guiyang. The tunnel site is in urban section and the ground construction (structures) region is extremely dense. The tunnel extending from west to east sequentially is getting through buildings (structures) such as Wenlian warehouse, Guikai road resettlement housing buildings No.2 and No.3, Guiwu transformer substation, Jinshi middle school which is under construction, Guiyang mental hospital, Baihua ditch, Baihuashan Road, Jinshi swimming pool, Baihuashan housing area, Wandong garden and so on.

\section{OPTIMIZATION OF BLASTING SCHEME}

\subsection{Blasting scheme}

According to the project, the tunnel rock mass is affected by tectonic, the engineering geological conditions is worse and there are ground buildings that need to protect. The damping demand is high. And each of cyclical footage must be controlled at about $0.5 \mathrm{~m}$, using partial and stairs excavation method, increasing free face and controlling the vibration intensity within the permitted safety range. The construction method is shown in Figure 2.

All units of data in Figure 2 are centimeter.

1. The excavation and support of circular bench in top bench of left tunnel

2. The excavation of top core bench in left tunnel 


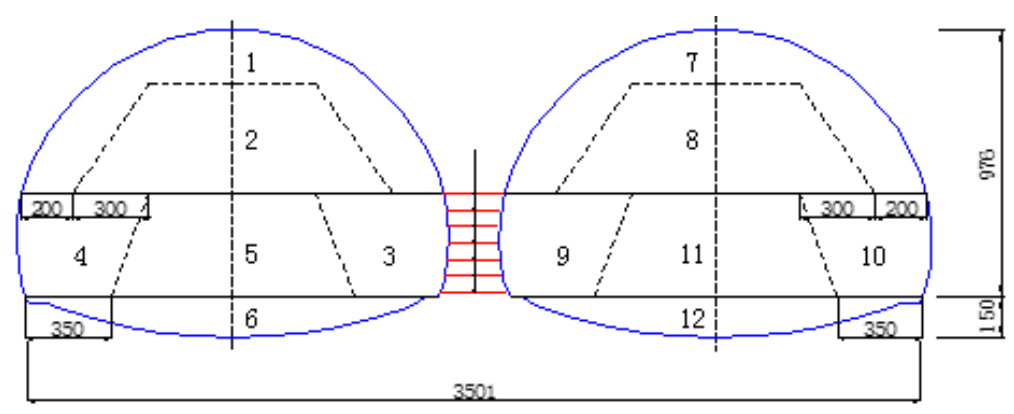

Figure 2. Bench method construction excavation blasting scheme

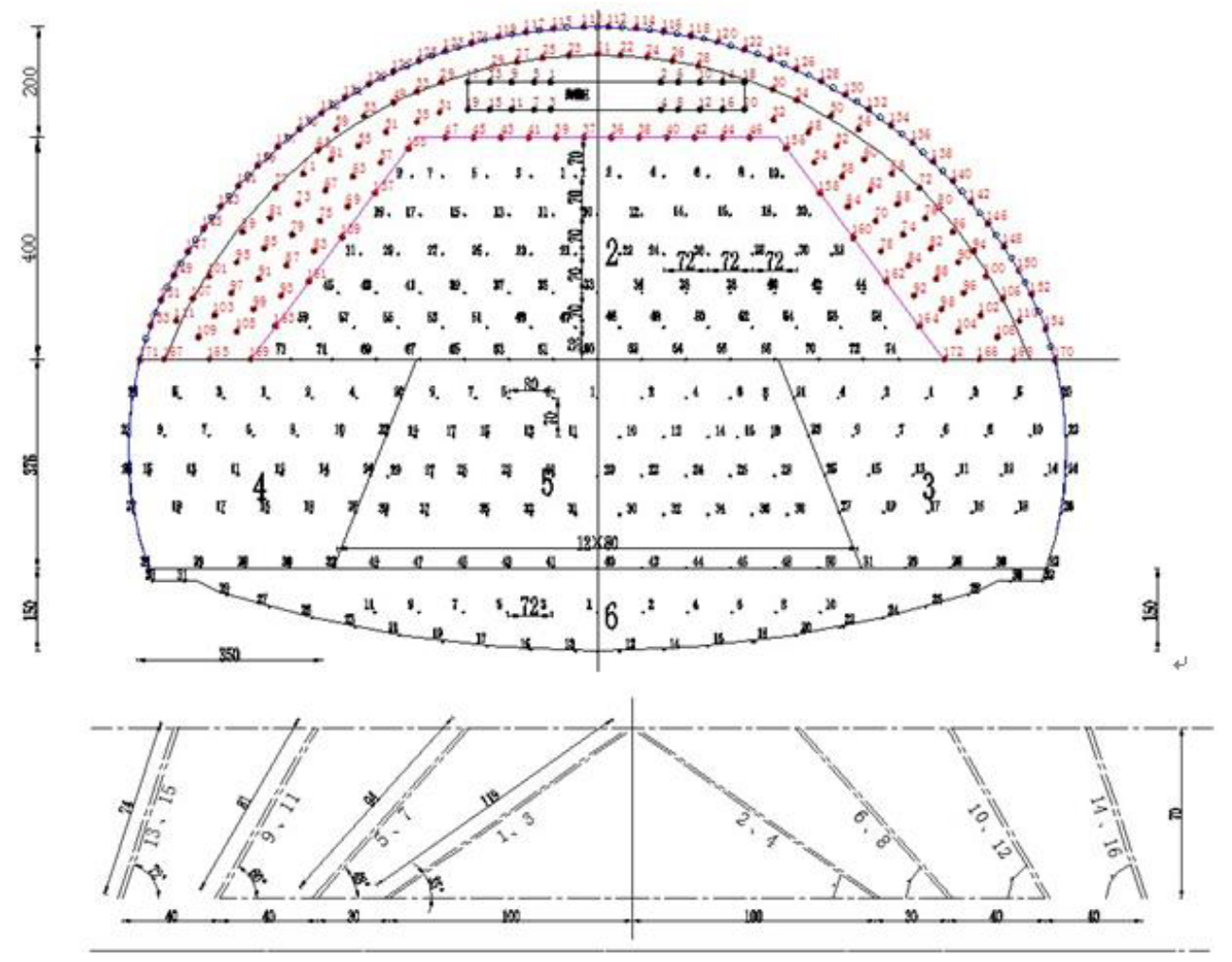

Figure 3. Step method construction excavation and the cutting hole layout diagram

3. The excavation and support of inboard bench in bottom bench of left tunnel

4. The excavation and support of outboard bench in bottom bench of left tunnel

5. The excavation of bottom core bench in left tunnel

6. The excavation of root bench in left tunnel

7. The excavation and support of circular bench in top bench of right tunnel

8. The excavation of top core bench in right tunnel

9. The excavation and support of inboard bench in bottom bench of right tunnel

10. The excavation and support of outboard bench in bottom bench of right tunnel
11. The excavation of bottom core bench in right tunnel

12. The excavation of root bench in right tunnel The length of blasting excavation unit is $0.5 \mathrm{~m}$.

\subsection{Blasting parameters design}

The blasting parameters are determined by theoretical calculations and engineering analogy method that combined with field test explosions. Improve the quality of molding tunnel excavation and construction schedule on the basis of guaranteeing the blasting vibration velocity that meets the safety requirements. 


\section{MATEC Web of Conferences}

Table 1. Step method blasting parameters list

\begin{tabular}{|c|c|c|c|c|c|c|c|}
\hline Position & & Hole site & $\begin{array}{l}\text { Hole space } \\
(\mathrm{cm})\end{array}$ & $\begin{array}{l}\text { Hole depth } \\
(\mathrm{cm})\end{array}$ & $\begin{array}{l}\text { Hole number } \\
(\mathrm{cm})\end{array}$ & $\begin{array}{l}\text { Single hole } \\
\text { dosage }(\mathrm{g})\end{array}$ & Remark \\
\hline \multirow{11}{*}{$\begin{array}{l}\text { The main } \\
\text { hole }\end{array}$} & \multirow{4}{*}{ Top bench } & Cut hole & $30 \sim 40$ & $74 \sim 119$ & $20 \times 2$ & 110 & \multirow{11}{*}{$\begin{array}{l}\text { Hole by hole } \\
\text { blasting }\end{array}$} \\
\hline & & Auxiliary hole & 50 & 70 & $85 \times 2$ & 75 & \\
\hline & & Periphery hole & 50 & 70 & $45 \times 2$ & $30 \times 3$ & \\
\hline & & Bottom hole & 50 & 70 & $22 \times 2$ & 150 & \\
\hline & \multirow{2}{*}{ Middle bench } & Driving hole & 80 & 100 & $59 \times 2$ & 150 & \\
\hline & & Bottom hole & 60 & 100 & $15 \times 2$ & 300 & \\
\hline & \multirow{3}{*}{$\begin{array}{l}\text { Side wall of } \\
\text { bottom bench }\end{array}$} & Driving hole & 80 & 100 & $19 \times 4$ & 300 & \\
\hline & & Periphery hole & 50 & 100 & $10 \times 4$ & $30 \times 3$ & \\
\hline & & Bottom hole & 70 & 100 & $3 \times 4$ & 450 & \\
\hline & \multirow{2}{*}{ Invert } & Bore hole & 80 & 100 & $11 \times 2$ & 300 & \\
\hline & & Bottom hole & 60 & 100 & $22 \times 2$ & 450 & \\
\hline
\end{tabular}

\subsubsection{Blast-hole depth $L$}

The blast-hole depth of this blast is designed to be adjusted by different blasting section, generally is $0.7-$ $1.9 \mathrm{~m}$.

\subsubsection{Number of blast-hole}

The designed blast-hole diameter is $42 \mathrm{~mm}$, each excavation area is about $10-37 \mathrm{~m}^{2}$ and the number of drilling in unit area is from 1.5 to 2.5 .

\subsubsection{Blast-hole arrangement}

The surrounding blast-hole arrangement is determined by empirical formulas and engineering analogy method. According to the blast-hole space $(E)=(8-12) d(d$ is the diameter of blast-hole); resistance line: $\mathrm{W}=$ (1.0-1.5) E. The design for the partition hole charge keeps empty holes as damping holes. The blast-hole space is $25 \mathrm{~cm}$, and the diameter is $42 \mathrm{~mm}$, which meet the requirements of $\mathrm{E}$ value.

Since the designed blast-hole space is $250 \mathrm{~mm}$, the similar engineering geological charging concentration is that $\mathrm{q}=0.1-0.15 \mathrm{~kg} / \mathrm{m}$, and it is charged in separated holes, so the designed charge concentration takes minimum value $(\mathrm{q}=0.1 \mathrm{~kg} / \mathrm{m})$. The cutting holes arranged are mainly used in the upper step of excavation. V-cut was used in blasting design. It is shown in Figure 3.

\subsubsection{Calculation of single hole dosage}

The blast-hole charge weight is calculated by the following formula:

$\mathrm{q}=\mathrm{k} \times \mathrm{a} \times \mathrm{w} \times \mathrm{L} \times \lambda(\mathrm{kg})$

In this formula: $\mathrm{q} \_$single hole charge weight

$\mathrm{k}$-explosive consumption

a_blast-hole space

$\mathrm{w}$ - resistance line in blast-hole direction

L_— blast-hole depth

According to the calculated values, $\mathrm{q}$ is $126 \mathrm{~g}$, and we control the largest single-hole charge by the amount of $120 \mathrm{~g}$.

\subsubsection{Blast-hole blocking}

The blocking effect is to make the explosives fully blasting constrained conditions in order to improve the energy utilization ratio, therefore, the block length should not be less than $20 \mathrm{~cm}$, and the plugging material uses stemming (the proportion of sand, clay and water is $3: 1: 1)$. The blocking is required to be dense without gap or intermittent.

\subsubsection{Choice of blasting equipment}

Use the modified ammonium nitrate fuel oil explosive and emulsion explosive. The surrounding blast-holes use small explosive cartridges $(\Phi 25 \mathrm{~mm})$, other blast-holes use standard explosive cartridges $(\Phi 32 \mathrm{~mm})$. High-precision digital electronic detonators are used. In order to avoid the stress superimposing of blast, each section of digital electronic detonator delay is in the range of $5-8 \mathrm{~ms}$. The cutting blast-holes are $5 \mathrm{~ms}$ and other blast-holes are $8 \mathrm{~ms}$.

\subsubsection{Charge structure}

The cutting holes and bottom holes use indirect initiation, and the surrounding holes use discontinuous decoupling charging form. To ensure simultaneous initiation of explosives in each surrounding holes, the detonating cord should be used to connect each segment of explosive cartridge.

\subsection{Test results of optimization scheme}

Through the optimization of blasting scheme and adjustment of blasting design parameters, using the optimized blasting scheme for site construction and after the blasting vibration monitoring, the following blasting vibration oscillogram can be obtained, the test values were within the accepted value of blasting vibration control, as shown in Figure 4.

As shown in the oscillogram, the blasting vibration peak is less than $0.5 \mathrm{~cm} / \mathrm{s}$, so it can be judged that the optimized blasting construction plan is reasonable and 


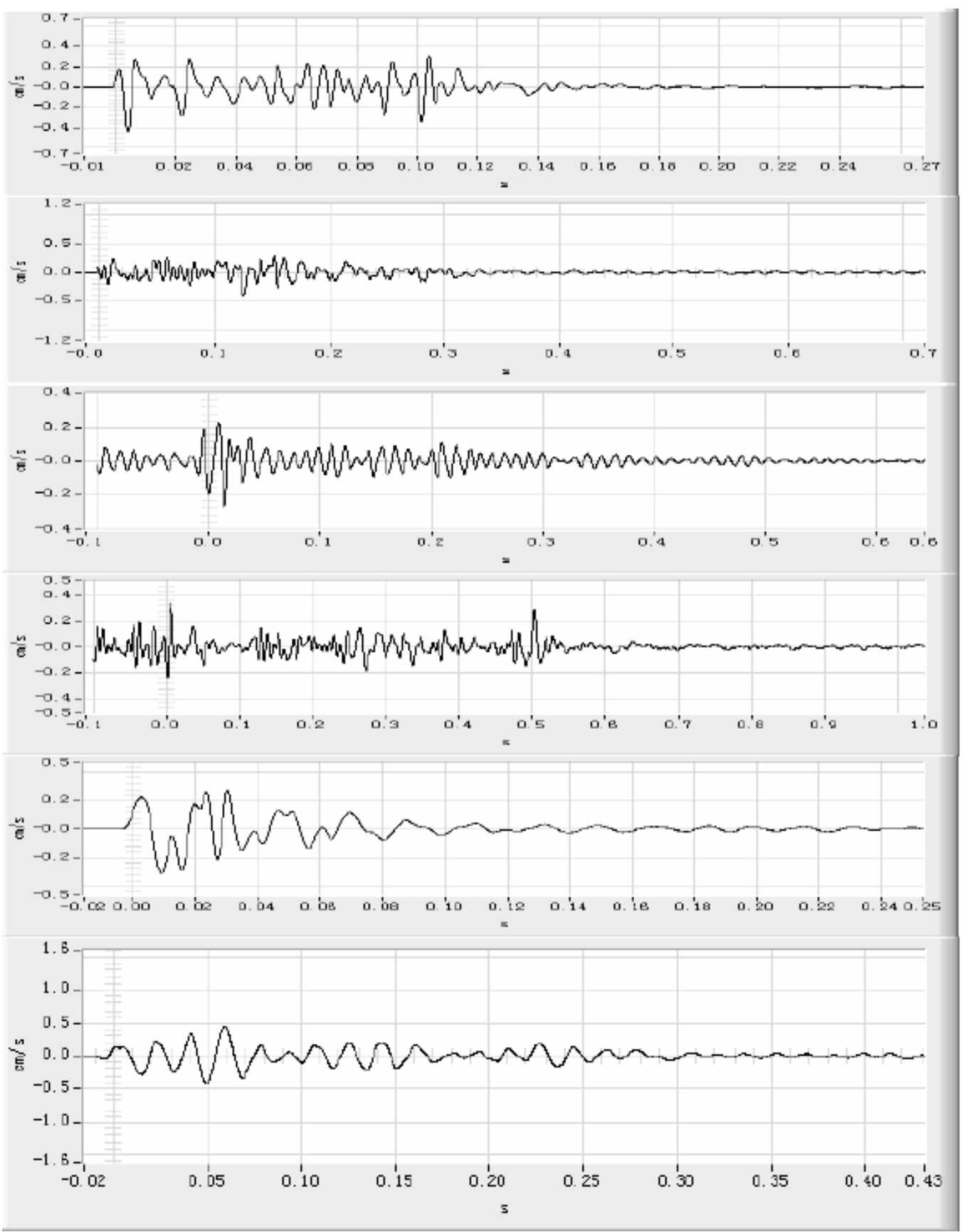

Figure 4. Blasting vibration oscillogram

feasible and has practical guiding significance to the project.

\section{CONTROL MEASURES OF REDUCING THE TUNNEL BLASTING VIBRATION}

Estimate each single segment (hole) charge, in this project construction, choose the particle vibration velocity limit of $0.5 \mathrm{~cm} / \mathrm{s}$ as control standard to inverse and calculate the permitted single hole dosage of each part.

(1)According to the environmental conditions and use micro footage division excavation, and each blasting cyclical footage is controlled at about $0.5 \mathrm{~m}$. It strictly controls the scale of blasting to achieve the 


\section{MATEC Web of Conferences}

purpose of controlling blasting particle vibration velocity.

(2)The blast-holes are arranged with principle of being shallow and dense, controlling the single hole dosage monocular loading dose, so that the limited charge dosage can be evenly distributed in the blast body and use high-precision digital electronic detonator for millisecond blasting, control each interval time difference in $5-8 \mathrm{~ms}$ and cut holes in $5 \mathrm{~ms}$ and other holes in $8 \mathrm{~ms}$. This will not only achieve the blasting effect, but also make interference seismic reduction. And it can also reduce the blasting seismic intensity to the greatest extent.

(3) The cutting holes should be arranged at the bottom of the division blasting section as much as possible in order to increase the distance from explosive source to ground surface in cutting area and reduce the cutting blasting vibration intensity to buildings.

(4) Use smooth blasting in the surrounding of excavation cross section, and set 1-2 empty holes between the blast-hole, which not only get control of under-excavation and guarantee the stability of surrounding rock itself, but also have the effect of shock absorption.

(5) The smooth blasting. The smooth blasting design used in tunnel contour is not only conducive to stability of surrounding rock and avoiding over under excavation, but also has the effect of vibration damping. The surrounding blast-holes uses low-detonation velocity explosive or small diameter cartridge coupling charging structure.

(6) Laid interference damping holes. Dense empty holes are arranged in the tunnel vault contour area, or just being an empty hole between two surrounding holes. It has two functions: First is damping effect; second is light explosion guidance effect.

\section{CONCLUSION}

The entire tunnel blasting scheme is optimized in consideration of engineering project, which is employed in construction trial on the spot. We obtain the corresponding blasting construction records and the blasting vibration test values, and then the peak of blasting vibration is strictly controlled below the specified value of $0.5 \mathrm{~cm} / \mathrm{s}$. Moreover, by employing rational blasting cut method, millisecond time, damping empty holes and smooth blasting, the hazard to surface struc- tures generated by blasting vibrations will be effectively controlled. The optimization of blasting schemes can substantially improve the construction efficiency and shorten the construction period, which will be a role of guide for the future engineering construction.

\section{REFERENCES}

[1] Zhang xueliang \& Huang shutang. 1981. Blasting seismic effects. Beijing: Earthquake Press.

[2] Ling tonghua. 2004. Blast vibration effect and initiative control of vibrational damage. Changsha, Central South University.

[3] Yang shengquan, Liao xiankui, \& Liu baochen. 2001 Default of the Judging Standard of Blasting Vibration Safety Abstract. Explosion and Shock Waves. 21(3):223-228.

[4] Zhu chuanyun, Lu wenbo, \& Dong zhenhua. 1997, Rock slope blasting vibration safety criterion review. Blasting. 14(4), 15-17.

[5] Wang wenlong. 1984. Drilling blasting. Beijing: Coal industry press.

[6] Vayong W \& Minxian C. 1990. Dependence of structure damage on the parameters of earthquake strong motion. European Earthquake Engineering. 19 (1):13-23.

[7] Chia-Ming Uang, \& Bertero V V. 1988. Implications of recorded earthquake ground motions on seismic design of building structures. EERC, University of California, Report No. UCBIEERC-/13:10-40.

[8] Haluk S \& Alphan N. 1995. Earthquake ground motion characteristics and seismic energy dissipation. Earthquake Engineering and Structural Dynamics, 24(9):1195-1213

[9] Krawinkler H, \& Nassar A. 1990. Damage potential of earthquake ground motions. Proceedings of 4th US National Conference on Earthquake Engineering, Palm Springs, pp:945-954.

[10]Uang C M. \& Bertero V V. 1990. Evaluation of seismic energy in structures. Earthquake Engineering and Structural Dynamics, 19(1):77-99.

[11]Leger P. \& Dssault S. 1922. Seismic energy dissipation in MDOF structure. Journal of Structural Engineering, ASCE, 118(5):1251-1269.

[12]Peter Fajfar, Tomuz Vidic. \& Matej Fischinger. 1989 Seismic demand in medium and long-period structures. Earthquake Engineering and Structural Dynamics, 18 (10):1133-1144. 